\title{
'Gene map' plan highlights dispute over public vs private interests
}

London. Leading geneticists from the United States, Europe and Japan are meeting with representatives of government agencies, private foundations and pharmaceutical companies in Washington next week to discuss launching an international effort to draw up a 'transcript map' of the human genome the next major step in understanding how the genome functions.

The goal of the meeting is to define a strategy for transferring the growing knowledge of biologically-active DNA sequences on to the physical map of the human genome, a preliminary version of which was published last year (see Nature 366, 698; 1994). Such a combination would provide important clues to identifying new human genes.

There is a wide consensus that a transcript map of the whole genome will be invaluable to both molecular biologists and geneticists, as well as to pharmaceutical companies keen to exploit related genes for diagnostic and therapeutic purposes. It is also widely felt that cDNA sequencing has reached a stage at which the creation of such a map, the estimated cost of which varies from $\$ 10$ million to $\$ 75$ million, is both timely and feasible.

But there is still a vigorous debate on the best strategy for moving forward. One key question to be addressed at next week's meeting, organized by the Wellcome Trust in London, is whether the construction of a gene map should be primarily a 'public domain' activity, or whether it can be safely left to research groups in the private sector (where over half of all research on the human genome is now carried out).

"Our hope is to develop strategies and identify possible funding sources for establishing an open and searchable DNA database which will be of value to the whole scientific community," says Tom Caskey of the Baylor College of Medicine in Houston, Texas, who will be chairing the meeting.

Craig Venter, president of The Institute for Genomic Research (TIGR) at Rockville in Maryland, whose group has already produced (and expects to publish within the next few months - see page 363 ) data on

\section{Merck to back 'public' sequencing}

London. The US pharmaceutical giant Merck Sharpe and Dohme is throwing down the gauntlet to its rival, SmithKline Beecham, over what it sees as the latter's attempts to corner the market on the commercial use of DNA sequences from the human genome.

In protest at the terms which it and other companies have been asked to accept in return for access to sequences generated by the Human Genome Sciences Inc. in Rockville, Maryland - in which SmithKline took a major stake last year (see above) Merck is about to announce plans to fund a separate sequencing operation, all the results of which will be placed unrestrictedly in the public domain through Genbank.

The sequencing will be carried out in the laboratory of Bob Waterston at the Washington University School of Medicine in St Louis. Merck has declined to confirm the costs of the project, which essentially involves duplicating the sequencing work of Craig Venter at HGS's Institute for Genomic Research (TIGR). But its contract with Waterston - which is expected to result in information of 200,000 DNA sequences being made public within a year - is reported to be worth around $\$ 5$ million.

Merck justifies its decision to back a 'public domain' database of sequences by claiming that, in requiring scientists to enter into strict agreements on the use of sequence information, HGS and TIGR have failed to meet earlier promises to make sequencing information publicly available. HGS's strategy is defended by George Poste, the research director of SmithKline. In an interview last week with The Wall Street Journal, he argued that, in addition to the SmithKline's pharmaceutical use of HGS's gene discoveries, "there's absolutely no reason why our genes can't be used as currency" in negotiating "creative alliance frameworks with various partners".

But Merck is challenging this philosophy. Without explicitly naming HGS, it claims that current restrictions on access to sequence libraries are likely to "slow progress" in the field.

"Clearly genomics is going to have an enormous impact on the way in which drug discovery goes forward," says Alan Williamson, vice-president of Merck Research Laboratories. "But we do not think that the human genome should be a proprietary thing; Merck believes strongly that basic biology is not proprietary."

HGS has rejected charges that its icensing policy is slowing up progress in research, or that the terms of its agreements are excessive. "Our data will soon be available to the entire scientific communty," says Venter. "If Merck wants access to it, then they should talk to HGS and SmithKline." Merck says that its approach "will ensure fair competition and prevent any organization from cornering the market on the human genome".

D. D. almost 200,000 individual expressed sequence tags (ESTs), feels that transferring such information on to a physical map of the genome is the next important step for molecular genetics.

"I have been arguing for a long time that if our sequences were placed on such a map, it would lead very rapidly to the discovery of the genes responsible for a large number of human diseases," Venter said last week.

Set against this enthusiasm, however, is a sharp debate over whether a transcript map should belong in the private or the public domain. Much of this debate has been triggered by tough demands which Human Genome Sciences Inc (HGS) -- the private company which provides the funding for Venter's TIGR, and last year reached a \$125 million agreement with the pharmaceutical company SmithKline Beecham - has been placing on scientists wishing to collaborate with them.

In particular, academic groups interested in working on genes for which HGS has already identified the possible DNA sequences have been asked to sign a "material transfer agreement" (MTA) assigning to HGS first rights to all uses of the gene in question. Although some groups have accepted these terms, others have refused to do so.

HGS has been modifying the contents of its MTAs in the light of outside criticism, and Venter claims he is confident that "a final solution will be reached which will be acceptable to the scientific community". But the experience of individual academic groups (as well as of research managers working for SmithKline's rivals, who have been unwilling to meet HGS's terms for collaboration with industrial partners) has been a prime source of current tensions over the 'ownership' of the proposed transcript map.

Some argue that the speed with which TIGR and other commercially backed operations have succeeded in producing medically useful information about the human genome suggests that fears about the implications of private conduct of the work are unfounded. They point out that all this information will eventually be accessible to academic researchers.

"If we can do things much quicker in the private domain, there is no reason why we should not do it [there]," says Daniel Cohen, director of the Centre des Etudes du Polymorphisme Humain (CEPH) in Paris, and head of the team which produced the first-generation physical genome map last year. (Venter and Cohen are already discussing a collaborative project to map Venter's cDNAs on to this map.)

But others argue equally fervently that the terms for collaboration that have been 
$\checkmark$ demanded by HGS make it essential for the transcript map to be compiled in the public domain, with as few restrictions as possible on who should have access to the data in contains, and on what terms.

"There has been concern voiced by a number of people that a considerable amount of effort is going outside the public domain, and that if [the results] are not going to be easily accessible, then the public domain needs a part in such an important venture," says Michael Morgan of the Wellcome Trust.

Some scientists go further to argue that allowing such a project to be dominated by the private sector will inevitably skew its priorities towards economic and industrial, rather than scientific, goals. "There is a public domain angle to all this, and therefore a need for a slight change in emphasis to make sure that all possible goals are covered," says David Bentley, head of human genetics at the Sanger Centre in Cambridge, Britain's main centre for genome sequencing work which is jointly financed by Wellcome and the Medical Research Council.

But others defend focusing sequencing and mapping activities on areas of the genome of potential value for diagnostic and therapeutic uses. "This is what people are waiting for," says Cohen. "Private companies can operate more quickly and efficiently than academic scientists, and for society, the quicker the work is done the better."

Wellcome officials hope that next week's meeting will provide an opportunity for open discussion between partisans of both points of view. But consensus is likely to be difficult to achieve.

Already there have been tensions caused by the fact that, according to Venter, neither SKB, HGS or TIGR have been invited to attend (even though representatives from several large pharmaceutical companies, such as Glaxo and Merck, will be there, as well as from some small gene-hunting companies, such as Sequana and Incyte).

Supporters of the 'public domain' approach argue that, in order to avoid the excessive influence of vested interests either from industry or governments - funding for a transcript map should come primarily from non-profit foundations.

In Britain, Wellcome is reported to be contemplating providing several million pounds to the Sanger Centre to work on the transcript map; other funds may be made available in the United States to groups such as researchers at MIT's Whitehead Institute in Boston.

But even the distribution of these funds is likely to prove controversial, as the motives of those favouring a 'public domain' solution are challenged by supporters of the 'private' approach on the grounds that, even if not motivated by financial rewards, the desire for scientific recognition may be playing an equally influential role in determining the position of any one institution in the general debate.

David Dickson

\section{Laboratory explosion prompts warning over gas supplies}

London. Researchers from the University of Umeå in Sweden, whose laboratory was wrecked last month by an explosion after a saboteur left the gas to all the Bunsen burners turned on, are urging other scientists to review their security arrangements to ensure that they avoid a similar fate.

The attack took place at the laboratories of the medical biochemistry department at the university, $700 \mathrm{~km}$ north of Stockholm. It has led Lars Thelander, head of the department, to question the need for central gas systems in modern laboratories.

One laboratory was completely burnt out in the explosion, which took place on 29 August, and which some staff members think might have been triggered by reports of events at the Rockefeller University in New York (see Nature 370, 315; 1994).

A technician found the doors to one of the laboratories on the sixth floor closed, when they were usually left open. She smelt burning, and found a peristaltic pump on fire, which she managed to put out after calling the fire brigade.

Members of the fire brigade smelt gas when they arrived and found that the gas outflow pipe had been lit in another laboratory. As the firemen approached, a bottle of ethanol that had been moved deliberately to be near the flame, melted, caught fire and ignited the gas that had settled near the floor causing an explosion, burning two firemen and injuring the technician.

Reagents and equipment, including centrifuges, microscopes and water baths, worth about Skr500,000 (US\$65,100) were destroyed in the fire that followed. In all it is expected to cost Skr1 million to rebuild the laboratory.

Tor Ny, a professor of medical biochemistry whose laboratory was destroyed, says he is unaware of any motive for the attackor who may have been responsible for it.

Gas supplies to about a hundred Bunsen burners had been turned on and the doors closed in laboratories on the top three floors of the building. "The whole building was full of gas. It was just lucky that the whole building didn't go up," says $\mathrm{Ny}$.

Neither Ny nor Thelander believe that the attack was carried out by animal rights campaigners, as their laboratory carries out significantly fewer experiments on animals than the other laboratories in Umeå.

Thelander says that, even though "there are always people who are fired", staff relations at the laboratory are no worse than elsewhere. But several factors suggest that the culprit may be a current or former fellow scientist. One is that the saboteur or saboteurs must have had access to a key to enter the building.

Thelander also believes that the culprit must have been familiar both with the layout of the building and with chemical reagents and laboratory systems, in order to set up the fires and avoid getting hurt themselves.

Thelander says that only one of the laboratories housed in the six-storey building in which the explosion took place regularly uses the central gas system, and that it remained in place primarily because it was needed when the building was originally constructed. "There is now a move to close the central gas [supply] and get rid of the risk," says Thelander. "I'm sure many laboratories could do the same." Maggie Verrall

\section{US lifts block on returning waste}

Munich. Two ships containing highly radioactive spent fuel from four European research reactors were expected to dock early this week at Sunny Point harbour in South Carolina, after a federal appeals court overturned an injunction against their entry into the United States brought by South Carolina's governor, Carroll Campbell.

The court ruling averted a potential crisis in which the ships, each carrying a cargo of 153 spent fuel rods containing bomb-grade highly enriched uranium (HEU), would be unable either to dock in the United States, or to return home to Europe.

Last June, the US Department of Energy (DoE) agreed to accept 409 spent fuel rods (which it had originally provided), in exchange for an agreement on the part of six research reactors in Europe to convert to more expensive (but safer) low enriched uranium.

These plans were upset earlier this month when Campbell sought to prevent the ships from unloading their cargo in the United States, arguing that the DoE's plans for the storage of nuclear waste represent an environmental hazard which has not been properly assessed.

Environmental groups joined the DoE and research reactor owners in challenging the injunction because of the ships' vulnerability to terrorist attacks (see $\mathrm{Na}$ ture 371, 192; 1994). The federal court's ruling has deflected further immediate embarrassment. But it does not affect a second decision by the district court in South Carolina to conduct a full hearing in late October over a further 256 fuel rods, due to be shipped from Europe in December. 